\title{
Two centuries of fossil fuel energy
}

The global demand for fossil fuel grew substantially over the 30-year period following World War II. After this, the oil price increases of the 1970 s led to conservation and improved efficiency, such that we have seen a flattening of per capita energy consumption over the past 15 years.

In looking at the future of energy consumption, we must consider economic activity, population growth, and the costs of energy in forecasting whether the resource base will be sufficient to accommodate the projected increase in energy requirements over the next century. We also need to consider conservation, efficiency measures, and development of the resource base, as well as environmental acceptability.

As long as there is no obvious substitute, the world must rely on fossil fuels. However, producers need to develop the technology to assure that these fuels will remain an economically viable, environmentally suitable resource. In addition, consumers must reduce energy consumption through more efficient use of fossil fuels and the discovery of new technologies that require less energy consumption. (Ed.)

My task here is to deal with the future of fossil fuels, specifically the prospects of developing the world's oil, gas, and coal resource base. This includes the question of how much energy might be needed by the world over the next century, as well as what forms of energy might be available. The future cannot be predicted with any certainty, of course, but a reasonable scenario of the next century of global energy needs is used in order to have an organized way of discussing the world's likely energy options. I include in my discussion the impact that environmental considerations might have on my observations and conclusions.

Beyond the middle of the next century, significant quantities of additional energy supplies are likely to be needed. The projected global energy needs over the next 100 years will require substantially increased amounts of fossil fuels. Increasing world energy consumption will intensify the challenge of balancing energy needs with environmental, social, and economic concerns.

The history of energy consumption (fig. 1) is impressive, especially for the 30-year period after World War II when the growth in fossil fuel demand averaged in excess of 5 percent annually. The transition from one form of fuel to another (fig. 2) provides some valuable insights into the dynamics of the energy system and the

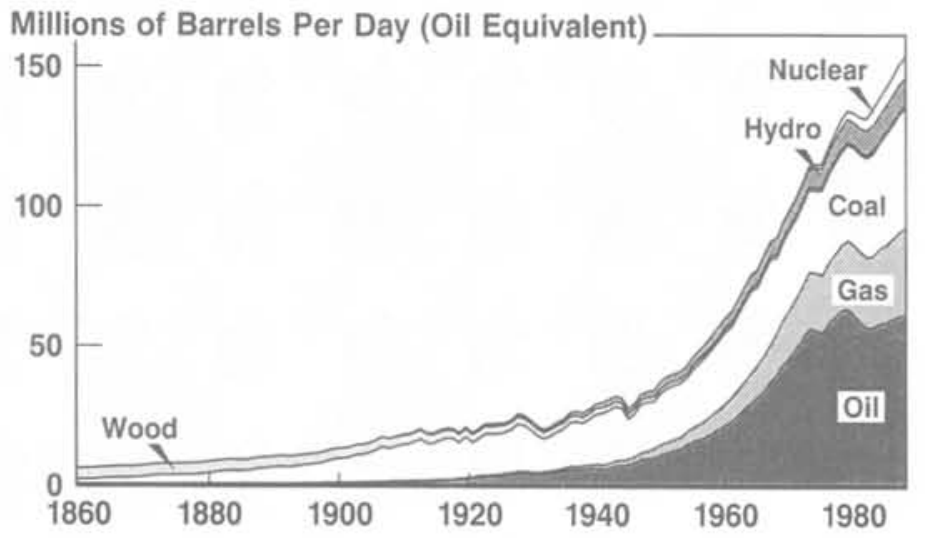

Figure 1.-The history of world energy consumption.

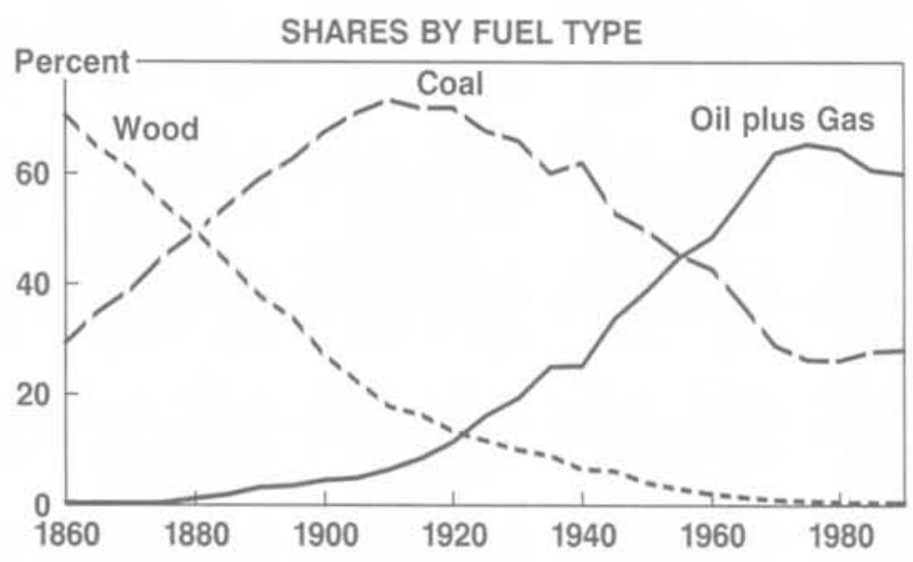

Figure 2.-The history of world energy consumption showing the major fuel types and their percentages of the total energy consumption.

forces that helped shape it. For example, the displacement of wood by coal as the dominant energy form at the turn of the century was driven by new technologies, particularly the steam engine and the blast furnace. The later shift toward oil and gas resulted from their widespread use in home and industrial heating, as well as from inventions such as the internal combustion engine.

Although technology played a role in stimulating the demand for fossil fuels, it also helped provide the ability to satisfy that growing demand-in fact, surplus producing capacity existed throughout the 30-year period after World War II. Let me give one simple illustration of the role technology has played in supplying fossil fuels. At one time, exploring for subsurface anticlines that might contain hydrocarbons depended on finding their expressions in the surface geology, preferably with nearby oil seeps. The invention of seismology improved our ability to define the subsurface structures that had no surface expression, which gave the industry new life and direction. Numerous other examples of similar contributions include organic 
geochemistry, digital recording methods, the discovery of seismic amplitude anomalies, plate tectonics, and three-dimensional seismology.

The penetration of new energy sources into the global scene is a slow process. Nuclear power, for instance, has been growing over the last three decades but has captured only about 5 percent of the world's energy market. One reason for the slow penetration of any new energy source is the significant inertia in the system, including social, economic. and technological inertia. Lifestyles and personal preferences are slow to change and often require two or more generations to take effect. Resistance also will be present if the new source results in higher energy costs. And many facilities have lifetimes of 25-50 years or longer-refineries, power plants, and industrial buildings, for example. Thus, a new energy source that requires social and technological transitions, as well as substantial capital investment, may take several decades to establish itself.

Historic trends in energy consumption per capita (fig. 3) are also relevant to a projection of the future. After the rapid postwar growth, the oil price increases during the 1970s led to conservation and a focus on improved efficiency. In air travel, for example, improved engine and aircraft designs have resulted in a 50 percent increase in fuel efficiency (ton-mile per gallon) since 1973. Energy consumption per capita for the world has remained essentially constant over the past 15 years as a result of energy conservation, primarily in the industrialized countries. A key consideration for the future will be whether the industrialized countries continue to reduce per capita consumption as energy requirements increase in the developing countries. For this discussion, the different areas of the world have been grouped under the following headings:

- The industrialized countries-referring to the member countries of the Organization for Economic Cooperation and Development, namely the countries of Western Europe and North America plus Japan, Australia, and New Zealand.

- The centrally planned economies - referring principally to the People's Republic of China, the USSR, and the countries of Eastern Europe.

- The remainder of the world-referring to other countries at various stages of economic and industrial development.

In order to determine the adequacy of our resource base of fossil fuel, we have constructed a scenario of future energy needs in each of these three areas of the world. In this scenario, the patterns of energy consumption are correlated with economic activity and population growth (fig. 4). This relationship is sensitive to price, and indeed, the trends appear to have been affected by the oil price increases of the $1970 \mathrm{~s}$.

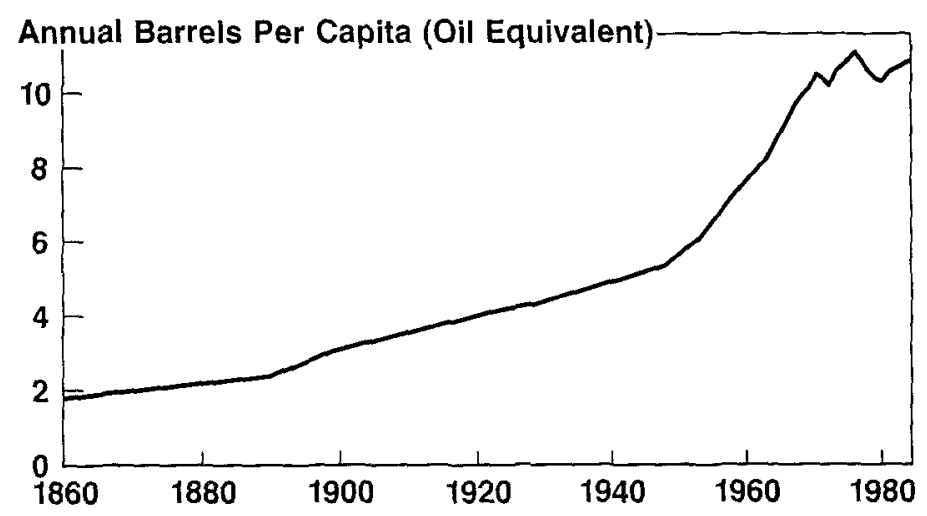

Figure 3. - The history of world energy consumption per capita.

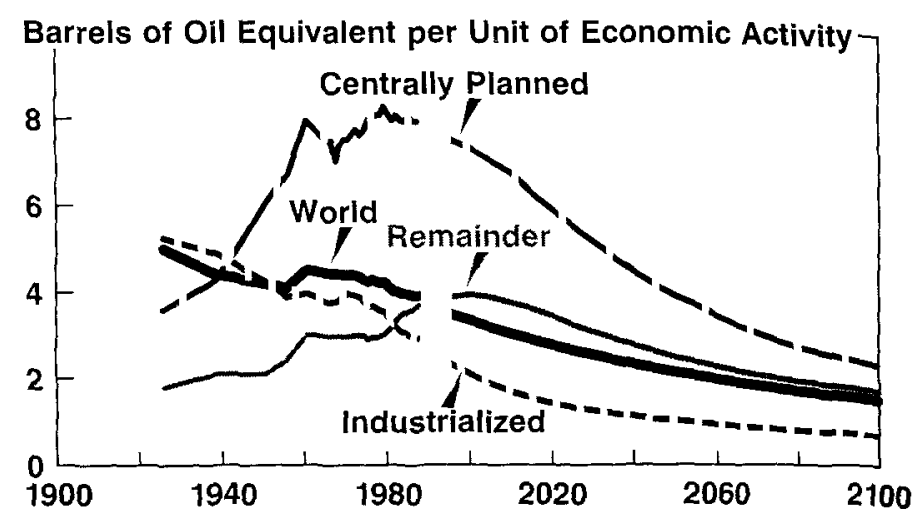

Figure 4. - The history and projection of energy consumption per unit of economic activity shown for each of three areas of the world and an average of the world.

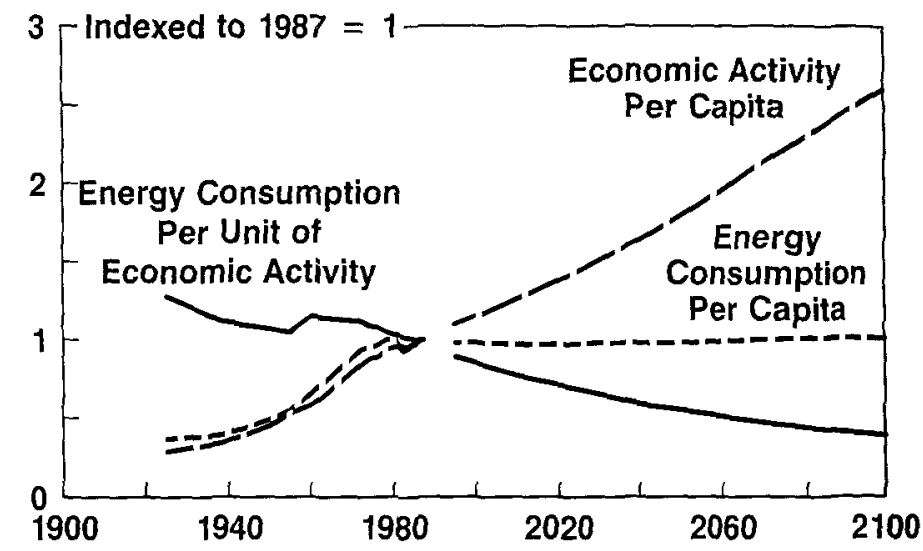

Figure 5. - The history and projection of world energy consumption and economic activity indexed to 1987.

In the industrialized countries, the ratio of energy consumption per unit of economic activity, often referred to as "energy intensity," has been decreasing for decades, but the rate of decline has been more rapid over the last 15 years. And I believe that it will continue to decline as additional technological improvements are introduced and countries restructure toward more technology-based industries and service-oriented activities, both of which are less energy intensive. Compared to the industrialized countries, the centrally planned economies currently consume a large amount of energy to produce a unit of economic activity, but that ratio has flattened and there are significant opportunities for energy savings in the future. Consumption in the remainder of the world probably will continue to increase, although the ratio should begin to decline early in the next century. This decline would result from the strong economic growth potential in many of these countries and from the transfer of technology from the industrialized world. If these forecasts are combined. we project that the energy intensity for the world will continue the declining trend established over the past 60 years.

The projection of future energy consumption on a per capita basis first requires a forecast of economic activity per capita, which is a measure of productivity. This will vary for the different countries of the world and will depend on the opportunities that exist to implement improvements in each country. Rather than present this analysis in detail, I will review just the global results (fig. 5). Like 


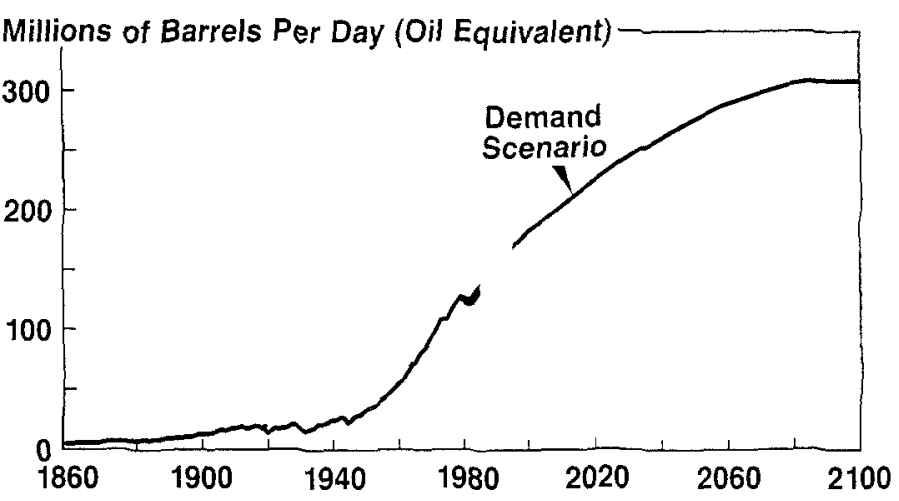

Figure 6.-A projection of world energy demand.

\section{CONVENTIONAL OIL AND GAS}

BITUMEN

SHALE OIL

COAL

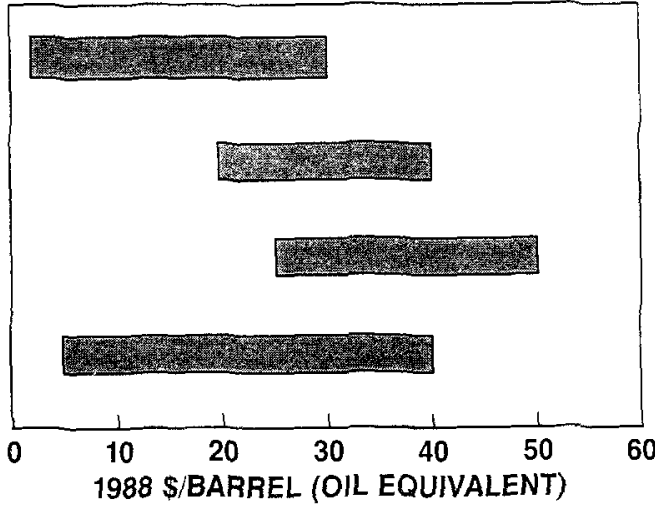

Figure 7. - Ranges of finding and development costs for various types of fossil fuels.

energy intensity, the projection of world economic activity per capita follows the trend of the past 60 years and shows potential for growth throughout the next century. Combining the projection of increasing economic activity with the decreasing trend in energy intensity results in a projection of energy consumption per capita for the world that remains essentially flat. This is a key consideration in the determination of future energy needs.

The extraordinary flattening of the energy consumption per capita ratio reflects a continuation of the remarkable technical and economic changes of the past 15 years. But even with these achievements, the population of the world is expected to double, at least. over the next century, and this will result in a projected doubling of the total energy consumption of the world as well (fig. 6). This would mean an increase from the current level of some 150 million barrels a day of oil equivalent to over 300 million barrels a day of oil equivalent in the year 2100 . Although this is certainly a substantial increase, it is comparable to the growth experienced during the last 100 years.

Certain pricing implications are inherent in this scenario. If the costs of energy (as a fraction of the overall economic activity) were to change dramatically. the projected patterns of energy consumption would be likely to change also. However, if we consider the economic growth expected over the next century and the flattening of energy consumption per capita. figure 5 indicates that the real price of energy could double without the total cost of energy exceeding its current fraction of world economic activity. Because energy intensity in the developing countries is expected to decrease also (fig. 4), a doubling of cost should not price energy out of their reach. Such price increases should give sufficient incentive to continue additional conservation and efficiency measures, as well as to develop the resource base of fossil fuel, including a substantial part of the world's bitumen, shale oil, and coal reserves (fig. 7).

The question remains as to whether the resource base is sufficient to accommodate the projected increase in future energy requirements over the next century. If not. what part of this demand scenario could we expect the fossil fuel supply to meet reasonably? To address that, let us consider the available options, first from a resource perspective (fig. 8).

For the oil and gas resource base. we have used the estimates from the U.S. Geological Survey report presented at the last World Petroleum Congress. This is the most recently published comprehensive study, and Shell's own view of the total resource is not materially different. The expected recovery volumes estimated in the report are 2 trillion barrels of ultimately recoverable oil and a nearly equivalent volume of natural gas. These figures include both the identified reserves and an estimate of probable future discoveries.

The recovery of an additional few hundred billion barrels each of oil and gas equivalent would be within the range of estimated uncertainty. For the purpose of our projection, we have included an additional 450 billion barrels of oil and gas equivalent. They are certainly possible as a result of additional exploration. improved drilling and recovery techniques, and increased energy prices. For instance, increasing the recovery efficiency for oil from the estimated 34 percent up to 40 percent would add some 350 billion barrels of crude oil alone.

The Middle East (fig. 9) contains some 38 percent of remaining global oil resources. Although North America consumes about 28 percent of the crude oil produced in the world, it has only 15 percent of the remaining conventional oil resources. However, North America possesses more than one-half of the world's bitumen and shale oil, as well as having major tar sand operations already underway in Canada. These unconventional resources potentially are available as real prices for oil increase.

The global natural gas industry (fig. 10) is still relatively young production to date being only 15 percent of the estimated ultimate resource. This conventional resource has the potential to be supplemented by gas trapped in tight sandstone, coal seams, and shale strata. Although gas is not as easily transported as is oil. especially on a global scale, the liquified natural gas business appears poised to make a recovery. Several projects that utilize spare capacity have been announced recently.

The coal resources (fig. 11) remaining in the world, based on a World Energy Council study, are equivalent to nearly 4 trillion barrels of oil, with large reserves in the USA, the People's Republic of China. and the USSR. Coal already supplies about 30 percent of the world's energy needs - and is likely to furnish a substantial fraction of future energy growth.

\section{BILLION BARRELS OIL EQUIVALENT}

\begin{tabular}{|lcc|}
\hline FOSSIL FUEL & ULTIMATE & REMAINING \\
\cline { 2 - 3 } OIL & 2000 & 1400 \\
GAS & 1700 & 1400 \\
UNCONVENTIONAL GAS & 1000 & 1000 \\
UNCONVENTIONAL OIL & 750 & 750 \\
SHALE OILS & $>1000$ & $>1000$ \\
COAL & 4500 & 3800 \\
\hline
\end{tabular}

Figure 8.-Estimates of fossil fuel resources of the world. 
Figure 9.-Global distribution of conventional oil resources.

Figure 10.-Global distribution of conventional gas resources of oil equivalent.

Figure 11.-Global distribution of remaining coal resources of oil equivalent.
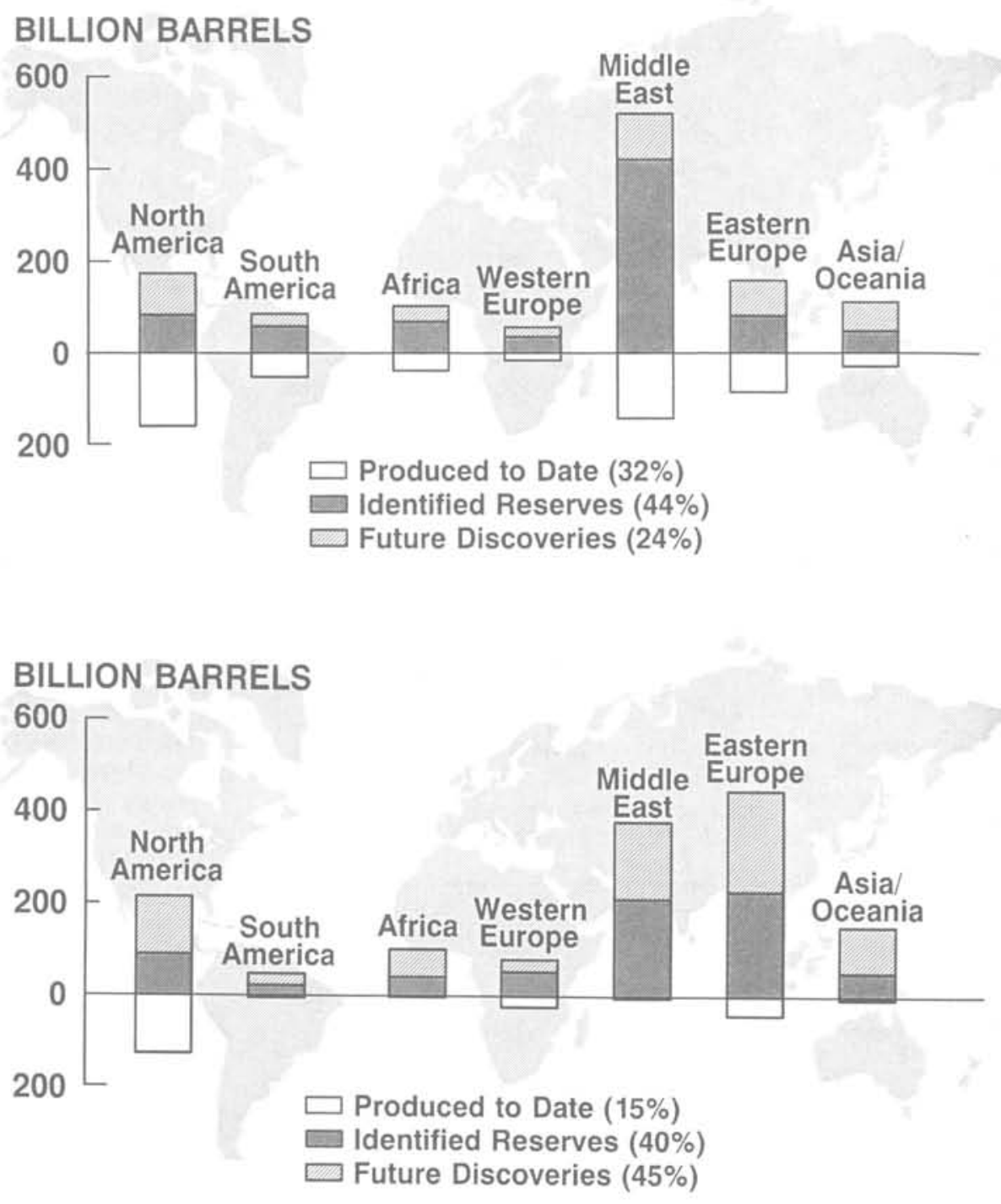

BILLION BARRELS

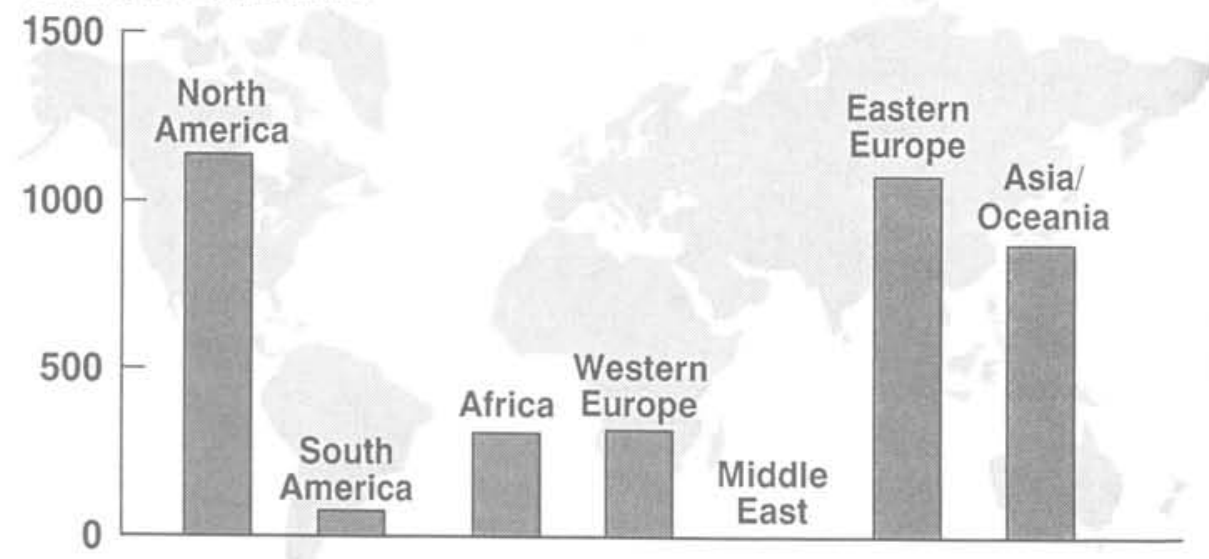


At present, the burning of coal and other fossil fuels in relation to the question of environmental acceptability is receiving a great deal of attention. Sulfur and nitrogen emissions with their resultant acid rain and other pollution effects are of concern, but technology is available to deal with them, albeit at some cost. More recently, the scientific community has focused on the gradual warming of the Earth. which some climatic models attribute to the increasing concentrations of carbon dioxide in the atmosphere-the accelerated greenhouse effect. Although these investigations are far from definitive and questions remain on the adequacy of the models and how to account for factors such as cyclic solar activity, prudence dictates that sensible measures be continued to reduce the emission of potentially harmful gases through, for example, the efficiency improvements I spoke of earlier. Emerging technologies such as advanced coal gasification processes, coupled with combined cycle powerplants, release 20 percent less carbon dioxide than normal coal-burning powerplants release. Future advances make another 20 percent reduction probable. Incorporating improvements like these into the global power-generating system will mitigate potential problems that could otherwise result from a more rapid buildup of the greenhouse gases, if this proves to be of serious concern.

Having looked at future energy requirements and the fossil fuel resources, let me now put them together into what $\mathrm{I}$ believe is a plausible scenario of the response to these demands (fig. 12). Oil production is projected to continue to grow in the near term at a rate of about 1 percent per year to a peak of about 75 million barrels a day around the year 2010. Natural gas has somewhat more growth potential than oil, and annual increases of 2-3 percent are possible with peak production occurring between 2020 and 2040. I have assumed that the 450 billion barrels of additional oil and gas I mentioned earlier would not begin to contribute significantly in the next 25 years; thus, they probably would act to slow the production decline rather than increase the peak rate. This projected production of oil and gas depletes a substantial part of the currently estimated remaining conventional resource base.

Unconventional oil and gas, such as tar and shale, could contribute in a significant manner beyond about 2025, if the increase in energy prices is sufficient to justify the development costs. With improved technology, the size of the resource (fig. 8) potentially could support the production of more than the nearly 1 trillion barrels included in this forecast.

If we look at the contribution of coal (fig. 13) and if development continues at a reasonable pace, coal production would peak in the middle of the next century. At that time, the level of production would be more than twice the current global production rate, and by the end of the next century, the majority of the identified coal resource would be depleted.

The shortfall between projected demand and fossil fuel production potentially could be supplied over the next 40 years by an increased contribution from the nonfossil energy sources. However, this would require a doubling of nonfossil energy output over that time to a level of 35 million barrels a day of oil equivalents. Such an output would be a significant achievement, especially if we consider the current state of the nuclear power industry in many countries of the world and the fact that no new alternative energy technology appears ready to make a contribution measured in terms of millions of barrels a day of oil equivalents. This brings me then to my first conclusion: world energy needs likely will require a better-than-50percent increase in the fossil fuel production rate over the next 40 years, even if we allow for conservation and efficiency improvements. This increase would be equivalent to some 75 million barrels of oil a day-less than the increase of the last 40 years of 100 million barrels a day of oil equivalents but still a very great challenge.

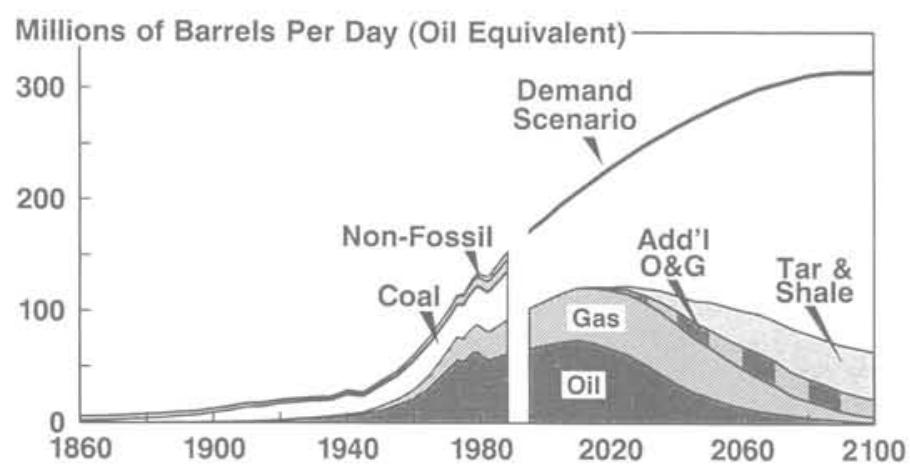

Figure 12.-Projection of future hydrocarbon production in response to global demand. The history of nonfossil fuels includes wood, hydro, and nuclear power (see fig. 1). Abbreviations: add'l $O \& G$, additional oil and gas.

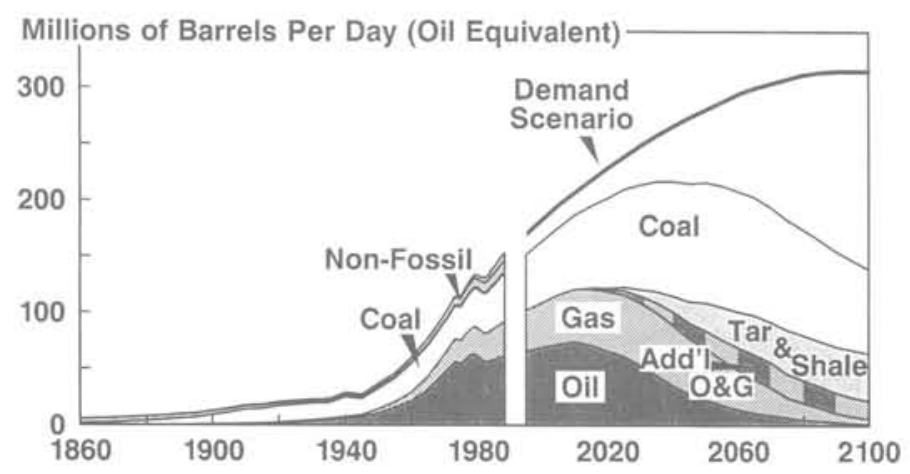

Figure 13.-Projection of future fossil fuel production including an increase in the amount of coal produced. See figure 12 for explanation of nonfossil fuel history and abbreviations.

Beyond the next 40 years, the projection is for an accelerating gap between the growing energy demand and the ability of today's fossil fuel resources to respond to this demand. Other coal resources possibly could be brought into production, but that would provide only a decade or so of delay until the demand for additional energy would accelerate again. This leads to my second conclusion: the need for energy supplies in addition to the fossil fuels included in this scenario probably will increase rapidly beyond the middle of the next century. This rapid increase most likely will occur even if there are no constraints imposed on the production of fossil fuels.

To illustrate the potential impact of imposing constraints on fossil fuel production for environmental or other reasons, let us examine one possible case (fig. 14). In this case, coal is assumed to be restricted to its current level of production, but the world energy demand follows a lower scenario. As in the higher scenario, oil and gas production, in total, is projected to increase $2-3$ percent annually during the next 20 years and, if we consider infrastructure and transportation limitations, probably could not be increased much more rapidly to compensate for the restricted rate of coal production. The world could respond by further reducing energy consumption per capita. Therefore, we developed a scenario that would result in a 20 percent lower demand by the end of the next century. In that case, nonfossil energy supplies would still need to be more than doubled between now and the year 2025 to make up for the projected fossil fuel shortfall, and the gap between supply and demand would continue to grow rapidly. Even if we assume the successful devel- 


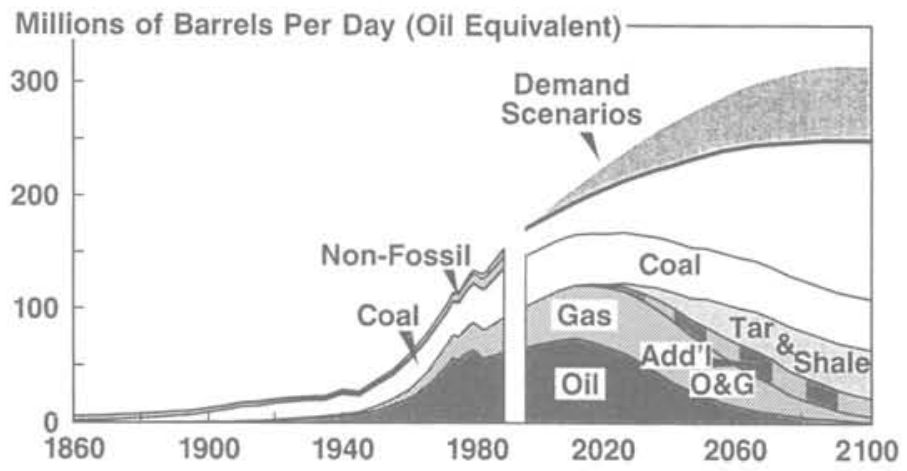

Figure 14.-Projection of future fossil fuel production if coal is constrained to current production levels. See figure 12 for explanation of nonfossil fuel history and abbreviations.

pment of alternative supplies, they are not likely to be able to grow this rapidly, and the total energy available to the world would likely be substantially less than the potential demand. This brings me to my third conclusion: restrictions on the use of fossil fuel could threaten economic growth and require changes in lifestyles - in the absence of some technological breakthrough not included in these scenarios.

How would the world be affected by this shortage of energy? The major impact most likely would be in the developing countries. My projection of energy demand assumed that the industrialized countries would continue to reduce their energy requirements through conservation and restructuring. Their net energy share during the next century (fig. 15) will be only about 20 percent of world consumption, because the population of these countries will be a small fraction of the world total. In contrast, the developing countries represent the majority of the projected growth in energy demand owing to their increasing populations and their move toward industrialization and the satisfying of basic human needs. In addition, some of these countries have a scarcity of other natural energy resources. This raises the question of whether curtailed fossil fuel consumption is a realistic option-or whether the more rational approach is the proliferation of the more efficient technologies and the continuing emphasis on additional improvements. Hence, this leads to my last conclusion: as long as no obvious substitute is available, the world must rely on fossil fuels and develop the technology to assure that they will remain an economically viable, environmentally suitable resource.

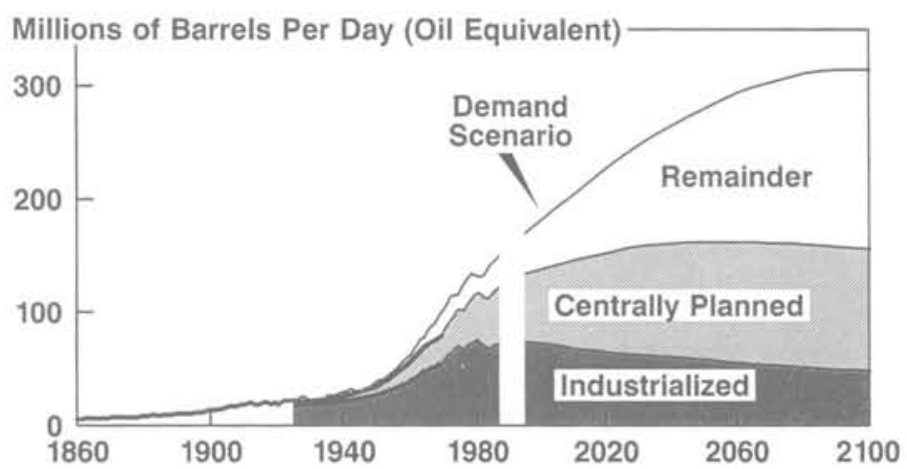

Over and above what might be expected reasonably from fossil fuel production, additional energy needs through the end of the next century may well exceed the growth of the entire fossil fuel industry (oil, gas, and coal) over the past century of development. I believe that technology improvements will permit the nuclear industry to overcome its problems and to be an important contributor in the future. And hydro power and solar energies likely will continue to develop and will make a modest contribution in meeting global energy needs.

Beyond the next 40 to 50 years, however, other major advances will be needed, whether they are new fusion discoveries, solutions to potential environmental problems, or breakthroughs that make available additional large volumes of fossil fuels. Breakthroughs also could come on the consuming side, perhaps motivated by environmental concerns, to reduce energy demand below the level in these scenarios. These breakthroughs might be in the form of still-moreefficient use of the fossil fuels or discovery of new technologies that would allow the continuation of economic growth but would require less energy consumption. Most likely, breakthroughs will come from a combination of efforts by both producers and consumers. In any event, satisfying future energy needs remains a challenge.

From its inception, the energy industry has been successful both in developing new technology internally and in adopting innovations from other industries. The energy industry has changed as both producers and consumers developed the technologies required to position themselves to accommodate a volatile oil market. The worldwide energy industry always has demonstrated considerable ability in adapting to a world of uncertainty and volatility when given orderly access to critical resources. I am confident that they will be able to do so in the future also and that technology will remain the key to fueling the world.

The energy future I have described is filled with challenges for producers, for consumers, and especially for the scientific community, whose dedication to research can play a large role in fostering economic growth and in improving the quality of life. I remain optimistic about the energy future. I see it not only as challenges that need to be overcome, but also as opportunities that wait to be seized upon and fashioned into the type of future that can be passed on to coming generations with confidence and with pride.

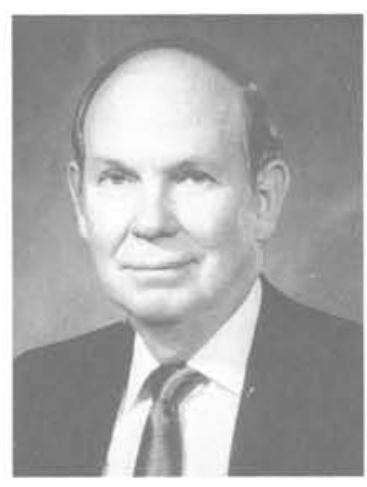

John F. Bookout served as President and Chief Executive Officer of Shell Oil Company from May 1976 through June 1988. He joined Shell Oil in 1950 as a geologist. Born in Shreveport, Louisiana, USA, Mr. Bookout graduated from the University of Texas with B.S. and M.A. degrees in geology. He is a member of the Supervisory Board of Royal Dutch Petroleum Company, a Netherlands company, and is also on the Board and Executive Committee of Shell Petroleum, Inc. He is past Chairman of the American Petroleum Institute and of the National Petroleum Council.

Figure 15.-Projected energy consumption, given by areas of the world. 